\title{
1 A unified approach to measuring structures in orientated drill core
}

2

3

4

$5{ }^{1}$ School of Earth and Ocean Sciences,

6 Cardiff University,

7 Main Building, Park Place

8 Cardiff CF10 3AT

9 UK

$10{ }^{2}$ Economic Geology Research Centre (EGRU),

11 School of Earth and Environmental Science,

12 James Cook University,

13 Townsville, QLD 4811,

14 Australia

$15{ }^{3}$ AngloGold Ashanti Ltd

16 Level 13, St Martins Tower

17 PO Box Z5046,

18 Perth, WA 6831

19 Australia

20

21 *Corresponding author: Tom Blenkinsop (email: BlenkinsopT@Cardiff.ac.uk)

22 Number of words (text, references, tables and figure captions): 4541

23 Abbreviated Title: Structural Analysis of Drill Core

Tom Blenkinsop ${ }^{1,2^{*}}$, Mark Doyle ${ }^{3}$ and Michael Nugus ${ }^{3}$ 


\section{Abstract}

26

27

28

29

A unified system of collecting structural data from drill core is proposed. The system encompasses planes and planar fabrics, lineations, fold hinges and hinge surfaces, faults and shear zones, vorticity vectors, shear directions and shear senses. The system is based on standard measurements of angles in the reference frame of the core ( $\alpha$ and $\beta$ angles), which are easily carried out by means of core protractors or templates. The methods for dealing with folds and kinematic analysis of shear zones have not been described previously, but they follow logically from the standard methods for dealing with planes and lines.

\section{Diamond drill core is arguably the most important source of data for mineral exploration and} development at the deposit scale. Since hydrothermal mineral deposits typically have strong structural controls, analysis of structures from orientated drill core is critical for the successful utilisation of such resources, as well as for understanding the geology of deposits. Many tens of km of drill core may be acquired for a single deposit during exploration before any ore is mined, and further drilling almost invariably occurs to investigate extensions of known mineralization once mining has started. An efficient method of structural data collection from drill core is essential to deal with this volume of data. Standardisation of the approach in production logging environments is a prerequisite for digital data capture, management and integration, improves the ability to identify discrepancies, and facilitates training of personnel. Structural analysis from drill core may be even more vital in future as exploration moves from well-exposed terrains into target areas obscured under deep cover.

Once drill core has been analysed, mineralised sections of the core are typically cut: half of the core is sent for assay. The remainder of the core is stored, commonly in an exposed manner where it can 
51 rapidly deteriorate, especially if it contains sulphides. Such core will need to be re-analysed if the

52 initial structural assessment is incomplete. This step is much more difficult from half core, more so

53 if it is weathered. Structural data collection from drill core therefore needs to be thorough as well as

54 efficient. A comprehensive structural analysis from the outset allows alternative ideas for deposit

55 genesis to be tested as the deposit is mined, and has major benefits for resource estimation.

57 Core is orientated by a variety of techniques during drilling (e.g. Marjoribanks 2009), which

58 generally result in a point being marked at the lowest part of the core - the bottom-of-core (BOC)

59 mark. The BOC mark is made at intervals (typically after each core run of a few m), and intervening

60 core is orientated by aligning adjacent BOC marks so that a continuous line can be marked along

61 the bottom of the core - the orientation ("ori" in typical Australian vernacular) line. Arrows are

62 commonly marked on the orientation line to indicate the down-hole direction. Fragmentation of the

63 core may degrade the quality of orientation, and other factors may also contribute to poor or

64 erroneous core orientation (e.g. Davis \& Cowan 2012). If limited drill core is available it may be

65 appropriate to mark an unconfirmed orientation line in a different colour and record structural data

66 collected from these intervals as unconfirmed. The minerals industry does not typically use

67 borehole imaging techniques (cf. Paulsen et al. 2002), so that core from vertical holes is difficult to

68 orientate; however, almost all exploration holes are inclined. The BOC mark and line is the basis of

69 all techniques used in this paper.

71 There are several methods of collecting structural data from orientated drill core (e.g. Marjoribanks

72 2009). Probably those most widely employed use various devices (template, rat-trap, core

73 protractor: Fig. 1) that specify the orientation of structures by measuring angles relative to the core

74 axis and the BOC line. Subsequently these measurements must be combined with data from the

75 down hole survey of hole orientation to retrieve the true orientation of structures. Because of the

76 universal tendency of drillholes to deviate, accurate survey data, specific for the depth of the 
measurement, must be used. The aim of this paper is to propose a systematic and unified system of collecting a comprehensive suite of structural data from orientated drill cores using angles measured in the core frame of reference. The basic methods for planes and lines are described first to show how new methods dealing with folds and shear zones can be developed logically from them.

The paper does not address the merits of various techniques of measuring structures in cores (described in Vearncombe and Vearncombe 1998), problems of core orientation, or procedures for reorientation of structures to a geographic frame of reference (e.g. Holcombe 2013; Stanley and Hooper, 2003)

\section{$\alpha-\beta$ Method - Planes and Planar Fabrics}

The $\alpha-\beta$ method for measuring planar features is in widespread use (e.g. Vearncombe and Vearncombe 1998; Marjoribanks 2009). The angles $\alpha$ and $\beta$ characterise the orientation of a planar feature. $\alpha$ is defined as the angle between a line parallel to the length of the core (the core axis) and the plane (Fig. 2). $\beta$ is the angle measured clockwise looking down core from the BOC line to the down-core axis of the ellipse formed by the intersection of the plane and the core (Fig. 2). The whole process of extracting a piece of core from a core tray, measuring $\alpha$ and $\beta$, and returning the core to the tray can be carried out in less than a minute, and is not subject to errors due to magnetic minerals that affect compasses.

\section{$\beta$ and $\gamma$ Methods - Lineations}

Lineations can be measured in two ways, both requiring the lineation to be interpolated through the centre of the plane in which it lies. A $\gamma$ measurement is similar to measuring the pitch of a lineation 
in a plane (Fig. 3), but the measurement is made with reference to the down-core end (long axis) of

102 the plane ellipse (cf. Holcombe 2013; $\gamma$ is defined differently in some literature e.g. Laing 1977;

103 Vearncombe \& Vearncombe 1998, but the Holcombe definition is used here). Alternatively, the

104 location of the lineation on the ellipse defined by the plane in which it lies can be used to define the

105 lineation orientation (Fig. 4). The point where the lineation, interpolated through the centre of the

106 ellipse, intersects the circumference of the ellipse can be measured by a $\beta$ angle (clockwise looking

107 downhole from the BOC mark) (Marjoribanks 2009), which is referred to as $\delta$ by Vearncombe \&

108 Vearncombe (1998). This measurement is distinguished here by the suffix L ( $\beta \mathrm{L})$ to distinguish it

109 from the simple $\beta$ measurement for a plane. This notation is introduced to avoid any possible

110 confusion with other Greek symbols, and to maintain consistency with the following methods. The

$111 \beta \mathrm{L}$ measurement can be combined with the $\alpha$ and $\beta$ measurements of the pane in which the lineation

112 lies, and the downhole survey data, to solve for the true orientation of the lineation.

114 There are two advantages to this method of measuring lineations: firstly, no additional equipment is

115 needed beyond the template/rat-trap/core protractor, compared to the $\gamma$ measurement that

116 additionally requires a conventional protractor. Secondly, as shown below, the $\beta$ method can be

117 extended to other lines (fold hinges, the vorticity vector), making it part of a unified way to collect

118 structural measurements from core.

\section{Folds}

122 Folds can have a complex expression on the cylindrical surface of a core, but typically they will

123 consist of a closed shape formed by the intersection of the core and the folded surface (Fig. 5). A

124 method for core analysis is required that can measure the orientation of both the hinge and the hinge

125 surface (axial plane). The hinge surface is simply dealt with by the $\alpha$ - $\beta$ method for planes. Because 
the hinge surface may not have a direct physical expression in a fold, it is useful to mark the surface

127 on the core to measure it accurately (Fig. 5b).

128

129 Hinges pose a more difficult problem than lineations, because the hinge surface in which they lie is

130 generally not exposed in the same way that lineations are seen on a foliation surface, and a hinge is

131 commonly a discrete line that does not pass through the centre of the core. This problem was

132 recognised by Scott \& Berry (2004), who proposed a method that uses three angles measured from

133 a transparent template to define the orientation of a fold hinge.

134

135 Here, a new method to measure fold hinges is proposed that uses $\beta$ angles, and a single length

136 measurement on the core (Fig. 6). $\beta \mathrm{U}$ is defined as the $\beta$ measurement of the up-hole intercept (U)

137 of the fold hinge with the core. $\beta \mathrm{D}$ is similar for the down-hole intercept (D). The distance UD is

138 defined as the distance between $U$ and $\mathrm{D}$ measured parallel to the core axis (Fig. 6). These

139 measurements can be combined to solve for the orientation of the hinge. Advantages of this method

140 are that it can be executed with a template/rat-trap/core protractor and a simple ruler, that it extends

141 the unified method developed here, and that it is simpler than the Scott and Berry (2004) method

142 that requires a special template. The method can be applied to any cylindrical fold defined by a

143 single layer, but disharmonic folds, and refold structures on the scale of the core, are difficult to deal

144 with.

145

146 Shear Zones

147 Structural analysis of shear zones requires measurements of foliations, lineation, shear plane, and

148 shear direction in mylonites, and determination of shear sense (Fig. 7). Foliations and shear planes

149 are readily measured using the $\alpha-\beta$ method, and lineations by the $\beta$ L method outlined above. The

150 shear direction was commonly taken as approximately parallel to the stretching direction as 
151 represented by the lineation, but particularly following the work of Tikoff and co-workers (e.g.

152 Tikoff \& Fossen 1993, Tikoff \& Teyssier 1994), it has been realised that this approximation is not

153 generally true, and that the relation between the shear direction and the lineation is a function of the

154 relative amounts of pure and simple shear, or the vorticity number (Fig. 7). Therefore a complete

155 analysis of shear zones requires measurement of the shear direction independently from the

156 lineation.

157

158 The key to making a comprehensive kinematic analysis of shear zones in core is the concept of the

159 vorticity vector. The vorticity vector is the axis about which internal rotation occurs in a shear zone

160 (e.g. Means et al. 1980; Xypolias 2010), which is perpendicular to the shear direction within the

161 shear plane (Fig. 7). The vorticity vector can be identified in a shear zone as the direction

162 perpendicular to the plane containing the maximum asymmetry of shear sense indicators, such as

163 winged porphyroclasts, asymmetric boudins, quarter structures, pressure fringes and shadows and

164 S-C fabrics (Fig. 8). This plane is also referred to as the Shear Sense Observation Plane, the

165 Vorticity Profile Plane, or the Vorticity Normal Section (Robin \& Cruden 1994; Jiang and Williams

166 1998).

167

168 Here core analysis has a significant advantage over outcrop geology. A single piece of core

169 intersecting a shear zone generally affords a complete view of the shear plane through $360^{\circ}$. It is

170 therefore possible to identify the vorticity vector relatively accurately compared to many outcrop

171 situations where this level of exposure does not exist. The vorticity vector can be identified as a

172 point on the core surface within the shear plane, and it can be measured by a single $\beta$ measurement

$173(\beta V$ : Fig. 9). This allows the shear direction to be calculated as the normal to the vorticity vector

174 and within the shear plane.

175

176

S-C and S-C' fabrics offer an alternative method for shear direction determination. The intersection

177 between $\mathrm{S}$ and $\mathrm{C}$ or $\mathrm{S}$ and $\mathrm{C}^{\prime}$ surfaces is perpendicular to the shear direction (Fig. 10). These 
surfaces can be measured by the $\alpha-\beta$ method, from which it is possible to calculate the shear

179 direction (SD), which lies in the $\mathrm{C}$ or $\mathrm{C}^{\prime}$ plane perpendicular to the intersection of the planes (Fig.

$1809)$.

181

182 Shear sense can be specified in several ways, depending on the orientation of the shear zones and

183 drill core, and user preference. The ideal situation is when the true orientation of the shear plane and

184 shear direction is known. In this case, the shear sense can be classified by qualitative kinematics i.e.

185 dip slip (normal, reverse), strike slip (dextral, sinistral), or oblique slip (dextral normal etc.). This

186 determination can commonly be made by holding the core in the approximate orientation that it was

187 drilled, and making a visual inspection.

188

189 However, in cases where shear planes are either approximately horizontal or vertical, it becomes

190 difficult to distinguish dextral from sinistral and reverse from normal without accurate reorientation

191 of the core, because the dip direction is uncertain. A second method can deal with these situations.

192 The uphole side of a shear zone can be unambiguously identified for all shear planes except those

193 through the core axis (Fig. 11). The shear sense can then be recorded as, for example: "The uphole

194 side has moved to the north" etc. Subsequently this record can be interpreted in kinematic terms

195 when the data is plotted on a stereonet: the uphole side is readily distinguished on a stereoplot as the

196 area that does not contain the core axis (Fig. 11). For planes that are parallel to the core axis, it is

197 usually possible to identify the two halves of a core in a third way: geographically. Thus it is

198 possible to state, for example: "the east side of the shear zone has moved north" etc. These

199 comments on determining shear sense also apply to faults.

201 In all three cases above, an alternative to describing movement directions is to specify the rotation 202 sense of the vorticity vector (clockwise or anticlockwise). It is essential to view the vorticity vector 203 in consistent direction: the convention of a downplunge direction is recommended. However, this 
direction can be difficult to establish for shear planes that are approximately horizontal. In such cases a downhole direction can be more readily established. The sense of rotation of the vorticity vector can be simpler to record than the shear sense as specified by movement directions.

\section{Half Core}

Core is commonly cut relatively soon after drilling for assaying. In some cases the half of the core with the orientation mark is regrettably sent for assay, in which case it is only possible to use the remaining half if some sort of reconstruction can be attempted from the adjacent core. Even if the orientation mark is preserved, however, it may not be possible to use the $\alpha-\beta$ method, because one or both ends of the ellipse formed by the intersection of the plane and the core are not preserved. A method that uses two linear measurements and one angle, on core of a specified diameter cut at a known angle to the orientation mark, has been developed to allow accurate measurements of planar orientations (Blenkinsop \& Doyle 2010).

\section{Discussion}

The most common industrial method of collecting structural data from core currently uses $\alpha$ and $\beta$ angles measured in a core frame of reference. The unified system for collecting structural data suggested here is based on these angles, with the addition in some cases of a length measurement. Therefore it can be taught easily, and readily incorporated into a standard structural measurement routine that enables efficient digital data capture and integration. A photographic method for collecting structural measurements (https://www.groundmodellingtechnologies.com/) utilises an image of core in a core tray: it remains to be seen how this could be utilised for vorticity vectors and fold 
hinges.

230 The early adoption of the unified system proposed here, while full core is available before it has 231 been cut for assay, may pay dividends at later stages of a mining project. Otherwise such core may 232 need to be revisited for additional structural measurements, particularly as new structural models 233 are developed. While it is possible to make measurements on half core by the methods in 234 Blenkinsop \& Doyle (2010), it is more time consuming, and there is less information available 235 compared to full core. In addition there is the risk of destroying core that contains the orientation 236 mark. The demand for larger sampling volumes in deposits with a high nugget effect (e.g. Dominy 237 et al. 2000) or for geometallurgical studies may necessitate complete destruction of core.

In response to the cost of obtaining drill core, new technologies are being developed that may replace some of the functions of core collection, by for example downhole logging and imaging

241 (http://detcrc.com.au/about/goals/). Coiled tubing drilling is also being investigated as an 242 exploration tool in the minerals industry (http://detcrc.com.au/programs/program-1/project-1-1/), 243 entailing no core retrieval. These developments reinforce the importance of utilising what may be very limited core to the fullest extent, and therefore the advantages of the system advocated here.

One potentially serious problem of using a core frame of reference is the possibility that structural measurements are collected but not processed until a later time when the core is no longer accessible. This means that the geologist has no ready appreciation of the geographical orientations of the features being measured while collecting data. Such a divorce between structural data collection and appraisal has several adverse consequences. Hypothesis development and testing is precluded until later. Anomalous observations or variations in orientations are not recognised, and cannot be allowed for in a data collection strategy. Therefore potential errors, including core 
254 be solved by immediate (real time) processing of core angle measurements on site. Ideally,

255 measurements should be entered directly into a logging form or spreadsheet that calculates the true

256 geographic orientations, and preferably plots them on a stereonet as the core is being logged. In

257 addition, the use of a "rocket launcher" is strongly advocated for occasional pieces of core, as a

258 check on the core angle measurements, and to convey a realistic picture to the geologist

259 (Vearncombe \& Vearncombe 1998).

260

261 This study has been based on core from structurally controlled hydrothermal mineral deposits.

262 However it is clear that petroleum cores also have a variety of interesting structural features (e.g.

263 Hesthammer 1998; Hesthammer \& Henden 2000; Porter et al. 2000; Hillier \& Cosgrove 2002).

264 With the availability of orientated and inclined core (e.g. Follows 1997), the techniques suggested

265 above could also be applicable in the hydrocarbon industry.

266

267

\section{Conclusions}

270 A unified system of structural observations in core is proposed, based on angles and lengths

271 measured in a core frame of reference. The system relies on the generalised use of $\beta$ angles,

272 combined with some linear measurements. It is capable of measuring planes, lines within planes,

273 fold hinges and hinge surfaces, and comprehensive analysis of shear zones and faults. Core is

274 particularly useful for the analysis of shear zones. The vorticity vector can be readily located, more

275 conveniently than in many outcrops, because of the full view of the shear plane afforded in core. All

276 the methods described for full core can be adapted for half core. Widespread use of, and familiarity

277 with, angular measurements on core makes for ready adoption of this unified method with modest

278 training requirements. Structural measurements from core may become even more important in the 
future as exploration moves under cover, and there is pressure to acquire less core.

280

282 Anglogold Ashanti Australia are acknowledged for access to the core on which this method was 283 developed. George Case provided some very helpful comments on a first draft.

284

285

286

287

288

289

290

291

292

293

294

295

296

297

298

299

300

301

302

303

304

\section{References}

Blenkinsop, T. G., \& Doyle, M. G. 2010. A method for measuring the orientations of planar structures in cut core. Journal of Structural Geology, 32, 741-745.

DAVIS, B., \& CowAN, J. 2012. Oriented Core-What the...In: Vearncombe, J. (ed) Structural Geology and Resources, Australian Institute of Geoscientists, Bulletin 56, 61-63.

Dominy, S. C., Annels, A. E., Johansen, G. F., Cuffley, B. W. 2000. General considerations of sampling and assaying in a coarse gold environment. Applied Earth Science, 109, 145-167.

FOLLOWS, E. 1997. Integration of inclined pilot hole core with horizontal image logs to appraise an aeolian reservoir, Auk Field, Central North Sea. Petroleum Geoscience, 3, 43-55.

HeSTHAMMER, J. 1998. Integrated use of well data for structural control of seismic interpretation. Petroleum Geoscience, 4, 97-109.

Hesthammer, J., \& Henden, J. O. 2000. Fault orientation from unoriented cores. American Association of Petroleum Geologists Bulletin, 84, 472-488.

Hillier, R. D. \& Cosgrove, J. W. 2002. Core and seismic observations of overpressure-related deformation within Eocene sediments of the Outer Moray Firth, UKCS. Petroleum Geoscience, 8, 141-149.

HoLCOMBE, R., 2013. Oriented drillcore: measurement, conversion and QA/QC procedures for structural and exploration geologists. http://www.holcombecoughlinoliver.com/. 
305

306

307 308

309

311

312

314

315

316

317

318

319

320

321

322

JiANG, D., WiLliamS, P. F. 1998. High-strain zones: a unified model. Journal of Structural Geology 20, 1105-1120.

LAING, W. B. 1977. Structural interpretation of drill core from folded and cleaved rocks. Economic Geology, 72, 671-685.

MEAns, W. D., HobBs, B. E., Lister, G. S. AND Williams, P. F. 1980. Vorticity and non-coaxiality in progressive deformation. Journal of Structural Geology, 2, 371-378.

MARJORIBANKS, R. W. 2009. Geological methods in mineral exploration and mining. Berlin; New York: Springer.

PAUlSEN, T. S., JARRAD, R. D., \& Wilson, T. J. 2002. A simple method for orienting drill core by correlating features in whole-core scans and oriented borehole-wall imagery. Journal of Structural Geology, 24, 1233-1238.

Porter, J. R., KniPe, R. J., Fisher, Q. J., FArmer, A. B., Allin, N. S., Jones, L. S., PAlfrey, A. J., Garrett, S. W. \& LEWIS, G. 2000. Deformation processes in the Brittannia Field. UKCS. Petroleum Geoscience, 6, 241-245.

RoBIN, P. Y. F., CRUDEN, A. R. 1994. Strain and vorticity patterns in ideally ductile transpression zones. Journal of Structural Geology 16, 447-466.

SCOTT, R. J., \& BERRY, R. F. 2004. A new method for obtaining and quantifying the reliability of structural data from axially-oriented drill core using a fabric of known orientation. Journal of Structural Geology, 26, 643-658.

STANLEy, C. R., \& HoOPER, J. J. 2003. POND: an Excel spreadsheet to obtain structural attitudes of planes from oriented drillcore. Computers and Geosciences, 29, 531-537.

TIKOFF, B., \& Fossen, H. 1993. Simultaneous pure shear and simple shear: The unifying deformation matrix, Tectonophysics, 217, 267-283, doi:10.1016/0040-1951(93)90010-H.

TIKOFF, B., \& TEYSSIER, C. 1994. Strain modeling of displacement-field partitioning in transpressional orogens. Journal of Structural Geology, 16, 1575-1588, doi:10.1016/01918141(94)90034-5. 
329 Vearncombe, J., \& Vearncombe, S. 1998. Structural data from drill core. In: Davis, B. and Ho,

$330 \quad$ S.E. (eds) More meaningful sampling in the Mining Industry,. Australian Institute of

331 Geoscientists, Bulletin 22, 67-82.

332 XYPOLIAS, P. 2010. Vorticity analysis in shear zones: A review of methods and applications. Journal

333 of Structural Geology 32, 2072-2092. doi:10.1016/j.jsg.2010.08.009

334

335

336 
339 Fig. 1. Some common tools for measuring structures in core.

340 a) Rocket launcher

341 b) Template (Scott and Berry 2004 version)

342 c) Rat-trap

343 d) Core protractor

Fig. 2. $\alpha-\beta$ method for measuring the orientation of planes or planar fabrics in orientated drill core.

$346 \alpha$ is the angle between the core axis and the long axis of the ellipse formed by the intersection of a 347 plane with the core. $\beta$ is the angle measured from the bottom-of-core mark to the ellipse long axis, 348 measured clockwise looking down core. The lower hemisphere, equal area stereoplot shows the 349 construction needed to find the true orientation of the plane using $\alpha$ and $\beta$, and the orientation of the 350 core. The plotting procedure is described in detail in Holcombe (2013).

352 Fig. 3. $\gamma$ method for measuring the orientation of a line within a plane. $\gamma$ is the angle from the 353 ellipse long axis to the lineation. Stereoplot shows $\gamma$ measurement.

Fig. 4. $\beta \mathrm{L}$ method for measuring the orientation of a lineation in a plane. $\beta \mathrm{L}$ is the angle from the bottom of core mark to the lineation within the plane, which can be measured readily with a core protractor. Stereoplot shows angular relationships and how to find the true orientation of the 358 lineation from the $\beta \mathrm{L}$ measurement and the orientation of the plane and core axis.

360 Fig. 5. Appearance of folds in core. a) Multiple folds in gneiss, expressed as figure of eight and 361 ellipses on the core surface. Folded surfaces marked in red dashed lines; fold hinge surfaces in 362 yellow. b) Fold hinges (yellow dots) and hinges surfaces (red lines) on adjacent folded surfaces. 
Both cores from Tropicana gold deposit, courtesy of Anglogold Ashanti Australia Ltd.

Fig. 6. Measurements needed to find fold hinge orientations from the intersections of a fold hinge on core. U, D are the up- and down-hole intersections of the hinge with the core. They are characterised by angles $\beta \mathrm{U}$ and $\beta \mathrm{D}$ measured from the bottom of core mark (BOC). UD is the distance from $\mathrm{U}$ to $\mathrm{D}$ parallel to the core axis, measured positive downhole.

Fig. 7. Appearance of two types of shear zone in core, with varying relationships between lineation and vorticity vector. The shape and orientation of the porphyroclasts are shown to be approximately representative of the shape of the finite strain ellipsoid. a) Simple shear dominant (sensu Tikoff and Fossen 1993). Lineation (yellow lines) is parallel to the shear direction. b) Pure shear dominant. Lineaton is parallel to the vorticity vector and perpendicular to the shear direction.

Fig. 8. Shear zones and shear sense indicators in core. a) Shear plane (yellow line on core) can be measured by the $\alpha-\beta$ method. The vorticity vector (purple line) and shear sense (yellow half-arrows) are identified within the shear plane by the $\sigma$ clast. The vorticity vector can be located by the angle $\beta \mathrm{V}$ from the Bottom of Core mark (BOC). b) S-C fabrics and vorticity vector in core.

Fig. 9. Measurement of the vorticity vector in core. The vorticity vector is located by the $\beta \mathrm{V}$ measurement from the Bottom of Core (BOC) measured clockwise looking down hole. The shear direction (SD) is perpendicular to the vorticity vector. Stereoplot shows angular relationships and construction necessary to locate the vorticity vector from the $\beta \mathrm{V}$ measurement, and the shear 385 direction $90^{\circ}$ from the vorticity vector in the shear plane. The vorticity is anticlockwise (looking down plunge), which implies a reverse sinistral sense of shear. 
389 direction (SD) and sense of shear. The S and C planes can be measured by the $\alpha-\beta$ method. The S-C

390 intersection is parallel to the vorticity vector, and perpendicular to the shear direction. The sense of

391 shear is given by the sense of rotation from the $\mathrm{S}$ fabric to the $\mathrm{C}$ fabric. Similar relationships exist

392 for $\mathrm{S}$ and $\mathrm{C}^{\prime}$ planes.

393

394 Fig. 11. Two situations in which kinematics are difficult or ambiguous to specify using typical 395 kinematic terms. a) It is difficult to specify the hangingwall of a near vertical shear plane. The 396 uphole side is unambiguous. b) It is difficult to know the exact dip direction of a near horizontal 397 surface, and therefore to evaluate whether it is dextral or sinistral. Again, the uphole side of the 398 shear is unambiguous. 



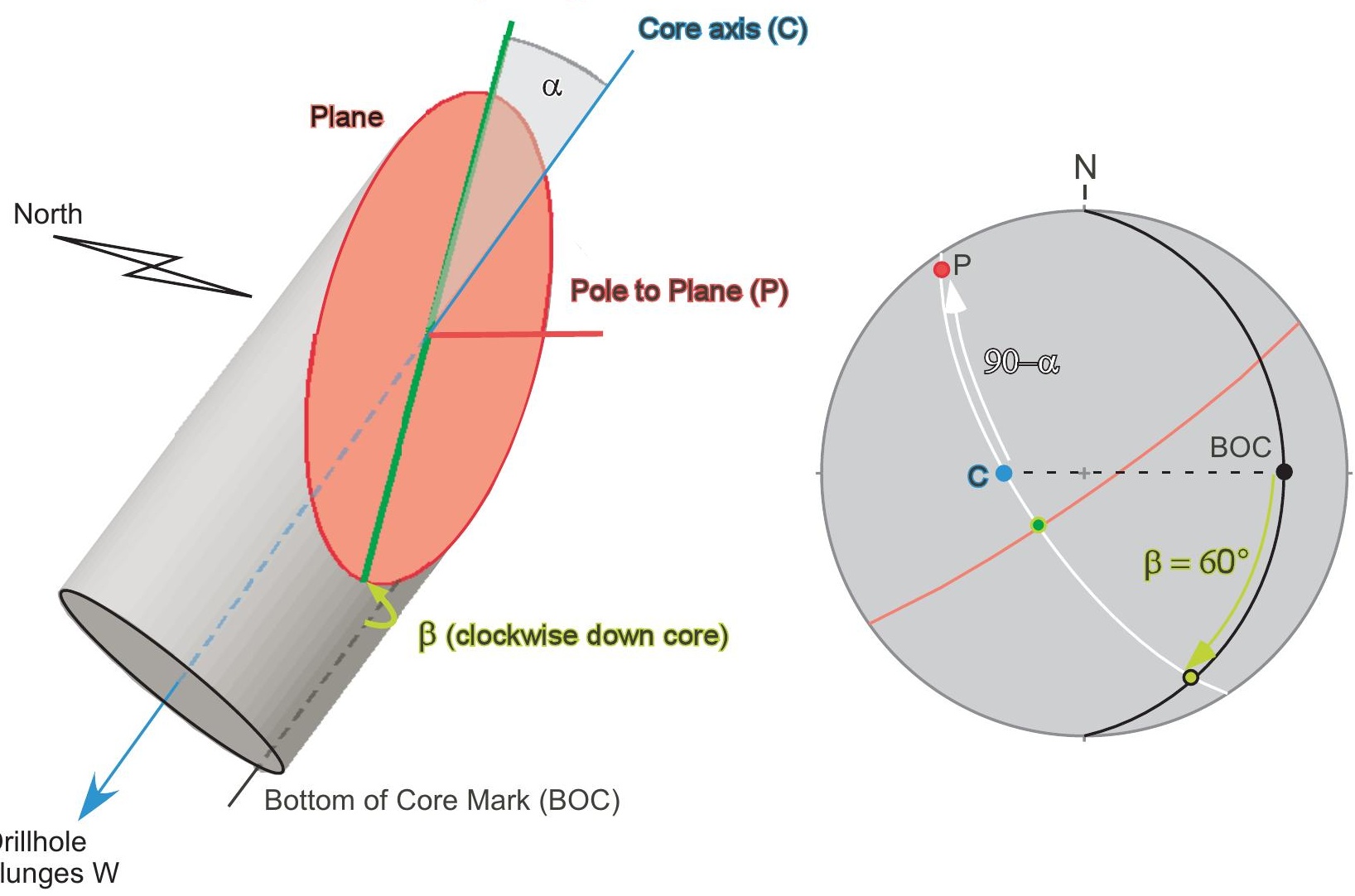





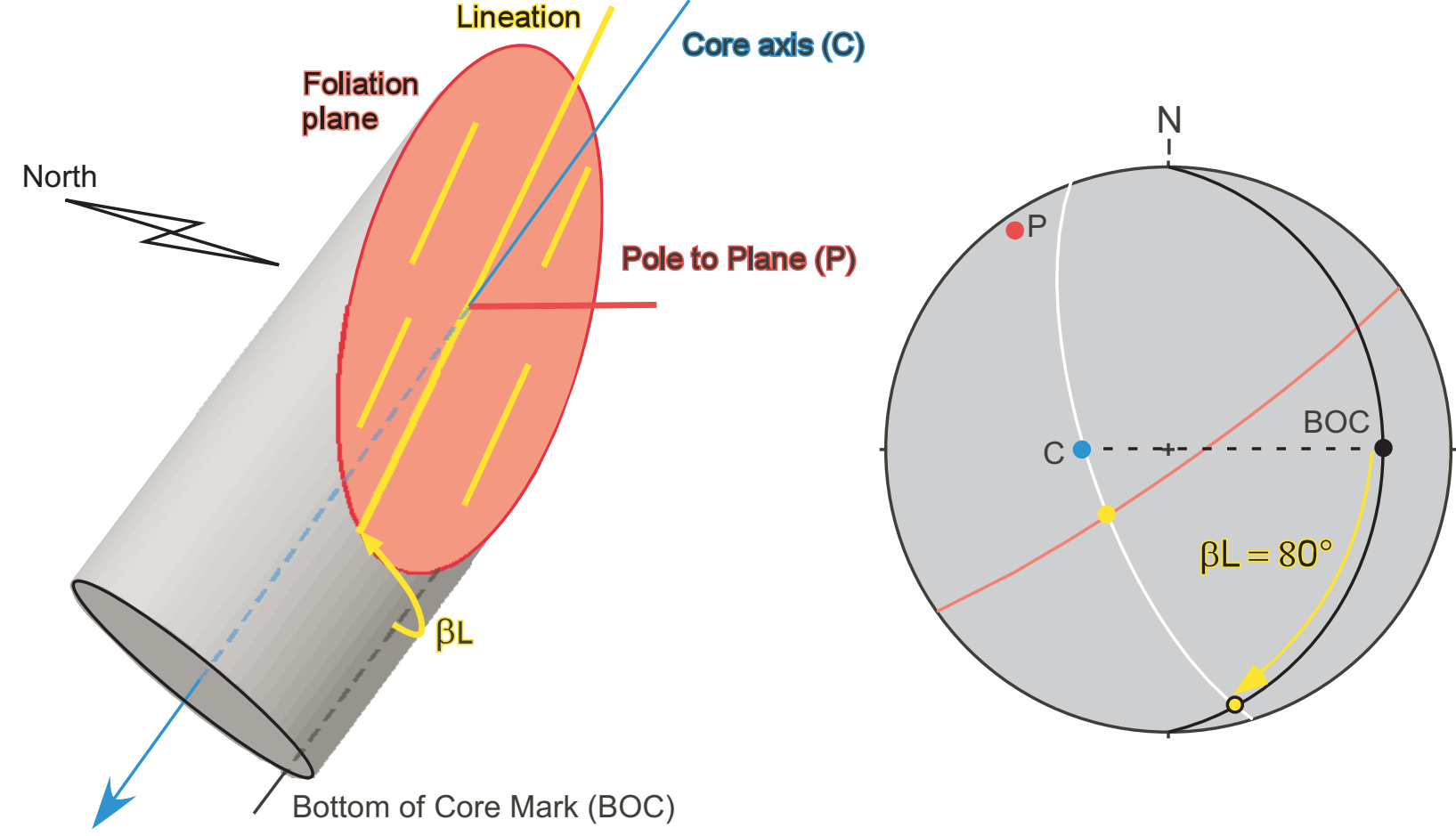

Drillhole

plunges W 
a)

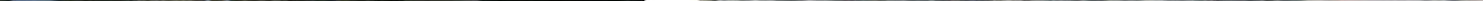




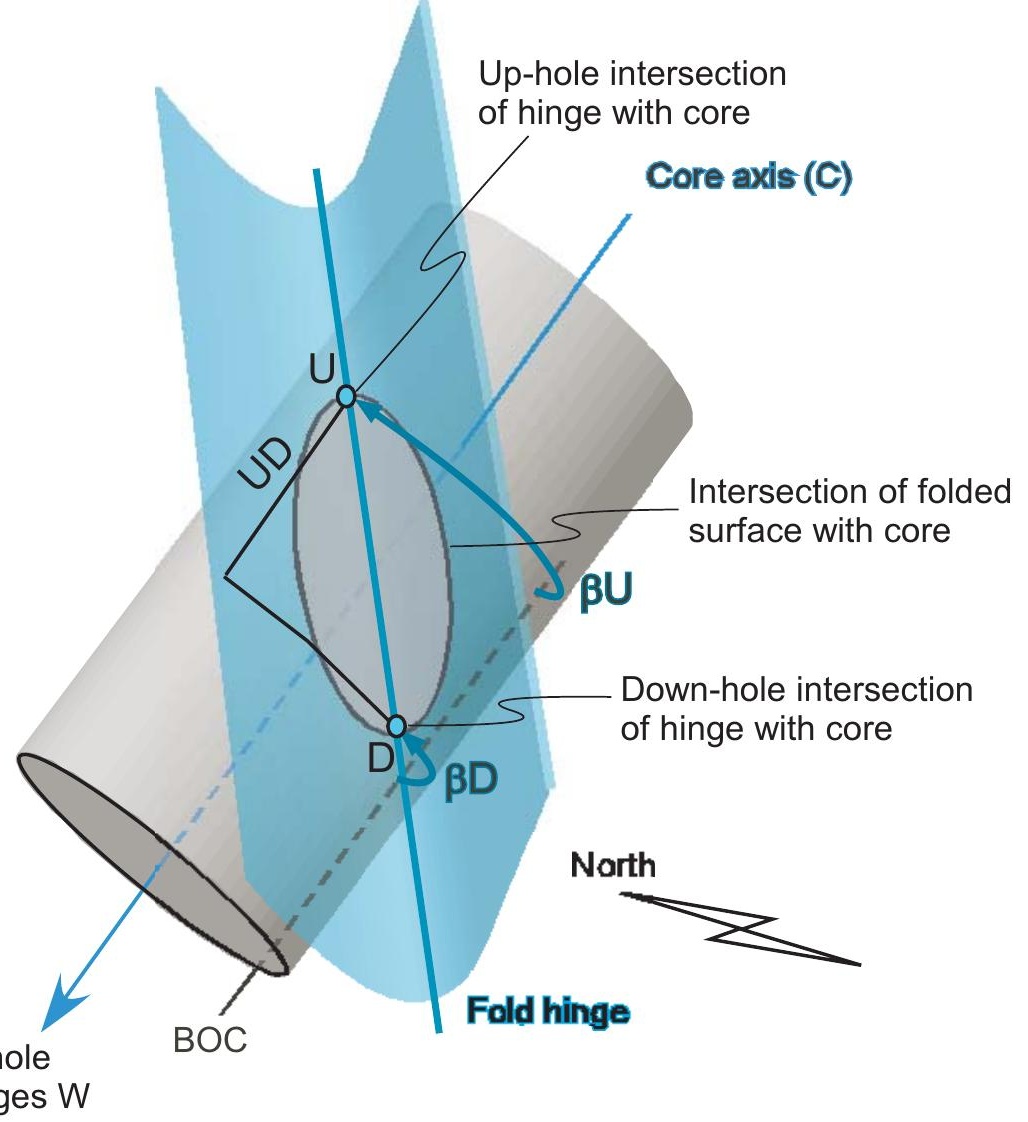


a)
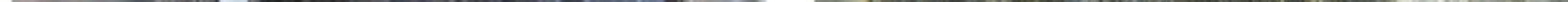


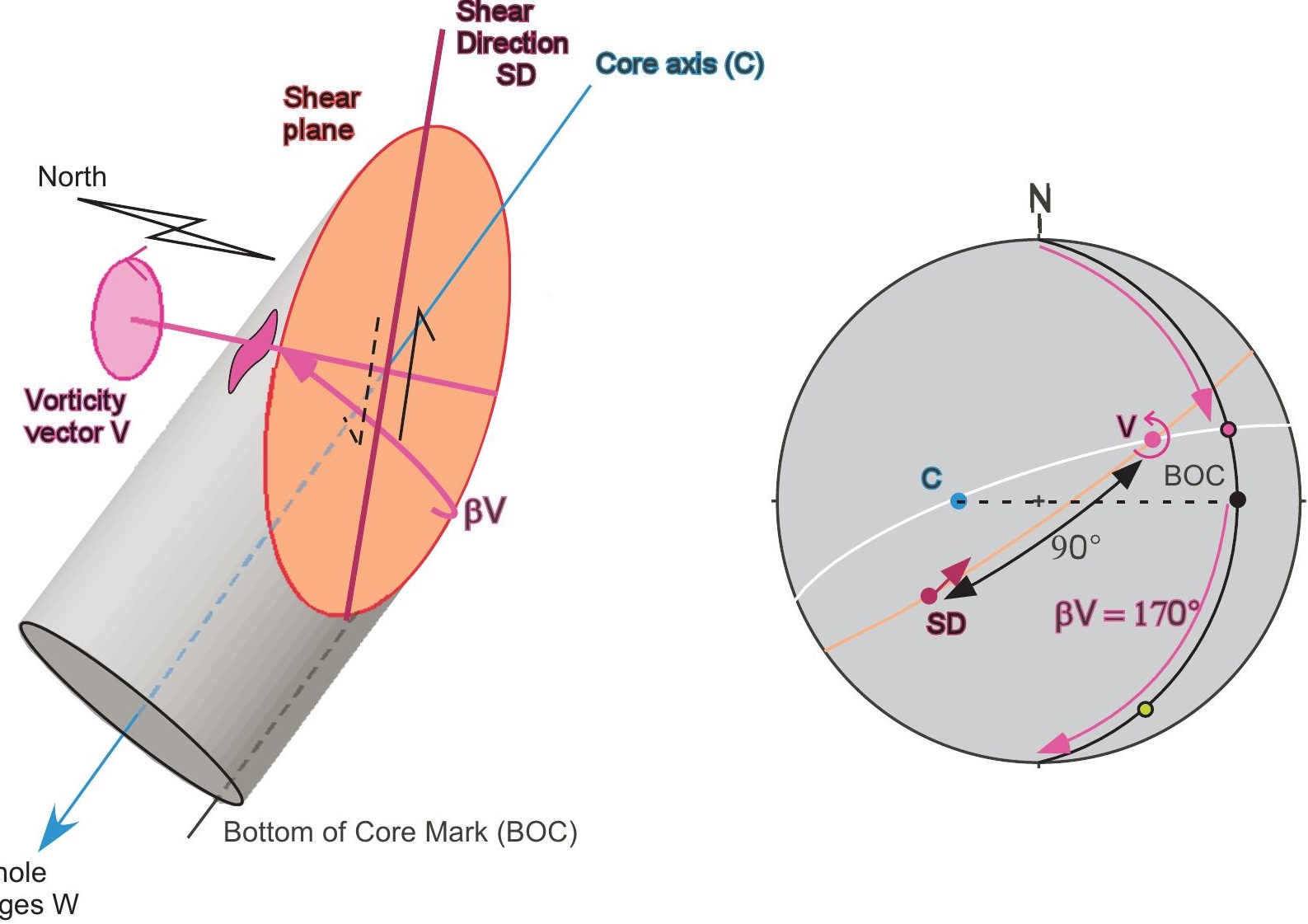


a)

Hangingwall? Footwall?

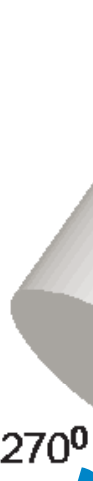

b)

UPHOLE side to South
UPHOLE side to North

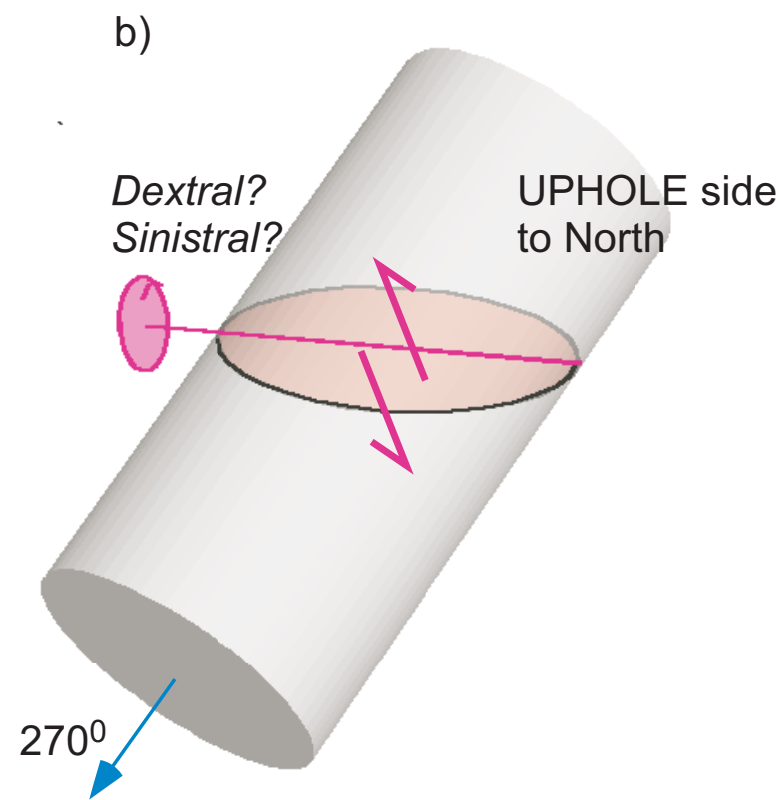

Dextral? Sinistral? 